\title{
Spontaneous Perforation of Colon: A Case Report and Review of Literature
}

\author{
Ahmed M. Makki*, Soha Hejazi, Nisar Haider Zaidi, Adel Johari, Abdulmalik Altaf \\ Department of Surgery, King Abdulaziz University, Jeddah, KSA \\ Email: ${ }^{*}$ dr.ahmed.makki@gmail.com
}

Received 25 May 2014; revised 24 June 2014; accepted 12 July 2014

Copyright (C) 2014 by authors and Scientific Research Publishing Inc.

This work is licensed under the Creative Commons Attribution International License (CC BY). http://creativecommons.org/licenses/by/4.0/

(c) (i) Open Access

\begin{abstract}
Objective: To present a case of spontaneous perforation of colon. Introduction: Spontaneous perforation of colon (SPC) is defined as sudden perforation of apparently healthy colon in absence of diseases or injury. SPC is an uncommon clinical entity which is seldom reported in literature, less than 100 cases were reported. Case report: A 82-year-old gentleman presented to emergency room (ER) with acute abdominal pain, for few hours duration. Pain started paraumbilically with sudden onset and then with increasing intensity became generalized. It was associated with nausea and vomiting. On general examination, he was conscious, alert. His vital signs: afebrile, pulse: 106/m, B.P: 140/100, local examination showed generalized abdominal tenderness \& guarding with absent intestinal sounds. P.R. exam showed remnants of stool with blood stain on gloves, no masses. Computerized tomography (CT) abdomen showed perforation of cecum. He was taken to operation room (OR) and right hemicolectomy was done. Post operative period was uneventful and he was discharged in good health. Conclusion: SPC is a serious condition with high morbidity and mortality due to delay in diagnosis and management so, every effort should be made to make diagnosis especially in elderly and prompt surgical intervention should be done.
\end{abstract}

\section{Keywords}

SPC-Spontaneous Colon Perforation, Cecal Perforation, Colon Perforation

\section{Introduction}

Spontaneous perforation of colon (SPC) is defined as sudden perforation of apparently healthy colon in absence of diseases or injury [1] [2]. SPC is an uncommon clinical entity which is seldom reported in literature, less than 100 cases were reported [3]. It is more common at the extremes of age especially elderly \& premature infants

\footnotetext{
${ }^{*}$ Corresponding author.
}

How to cite this paper: Makki, A.M., Hejazi, S., Zaidi, N.H., Johari, A. and Altaf, A. (2014) Spontaneous Perforation of Colon: A Case Report and Review of Literature. Case Reports in Clinical Medicine, 3, 392-397. 
but no age is exempted [4] [5]. It results in severe peritonitis with high mortality which should be considered in differential diagnosis of acute peritonitis with free air under diaphragm, as it always necessitates laparotomy [6]. It was described first by Brodie in 1827, a case of middle aged women whose rectum was spontaneously ruptured. We present a case of spontaneous perforation of colon in an elderly male patient.

\section{Case Report}

A 82-year-old gentleman presented to ER with acute abdominal pain, for few hours duration. Pain started paraumbilically with sudden onset and then became generalized with increasing intensity. It was associated with nausea and vomiting. He was known constipated and did not pass stool for three days. There was no history of bleeding per rectum. There was no history of anorexia and weight loss. He had appendicectomy done 30 years ago and transuretheral resection of prostate for beingn prostatic hypertrophy (BPH). On general examination, he was conscious, alert. His vital signs: afebrile, pulse: 106/m, B.P: 140/100, local examination showed generalized abdominal tenderness \& guarding with silent intestinal sounds. P.R. exam showed remnants of stool with blood stain on gloves, no masses. Blood works as CBC showed WBC: 5.40 HB: 15.4 gm/dl, other laboratory investigation were satisfactory. X-ray chest PA view showed no gas under diaphragm (Figure 1) while lateral chest X-ray showed gas under diaphragm (Figure 2). CT scan abdomen shows pockets of gas around caecal pole with pericaecal free fluid consistent with caecal perforation (Figure 3). CT scan abdomen shows marked thickening of caecum with fat stranding and free fluid (Figure 4). Intraveous (I.V) antibiotics in the form of cefuroxime \& metronidazole were started. Decision was made for exploratory laparotomy, during which a rounded perforation $1 \times 1 \mathrm{~cm}$ in diameter at the anterior surface of cecum was found. Seropurulent fluid was freely present in the peritoneal cavity with no fecal content. Right hemicolectomy with peritoneal

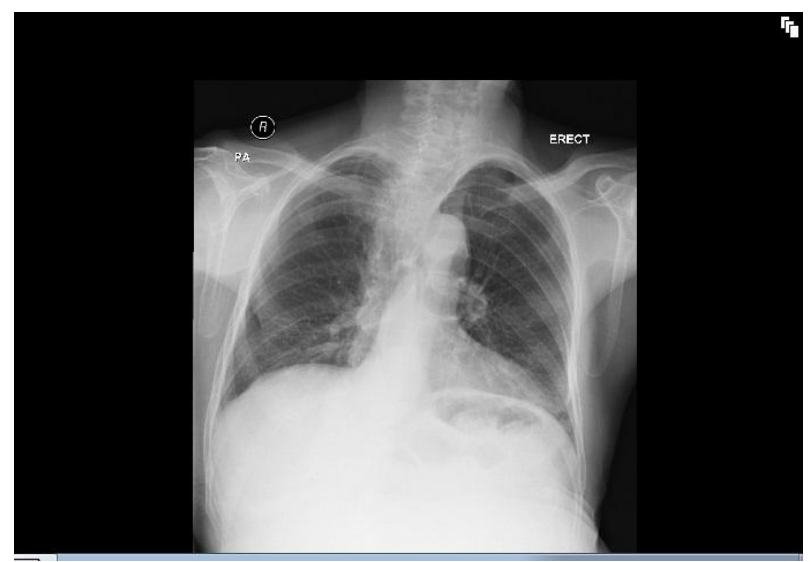

Figure 1. X-ray chest AP view-No signs of gas under diaphragm.

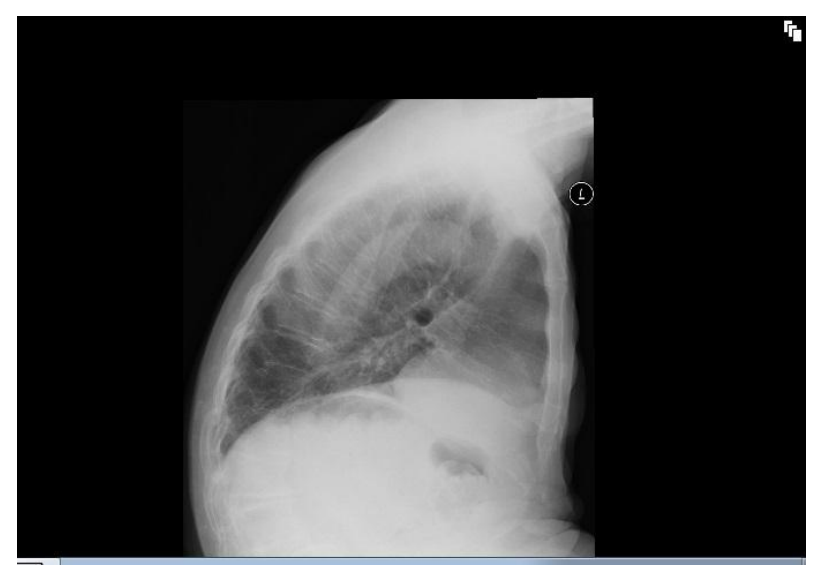

Figure 2. X-ray chest lateral view showing gas under diaphragm. 


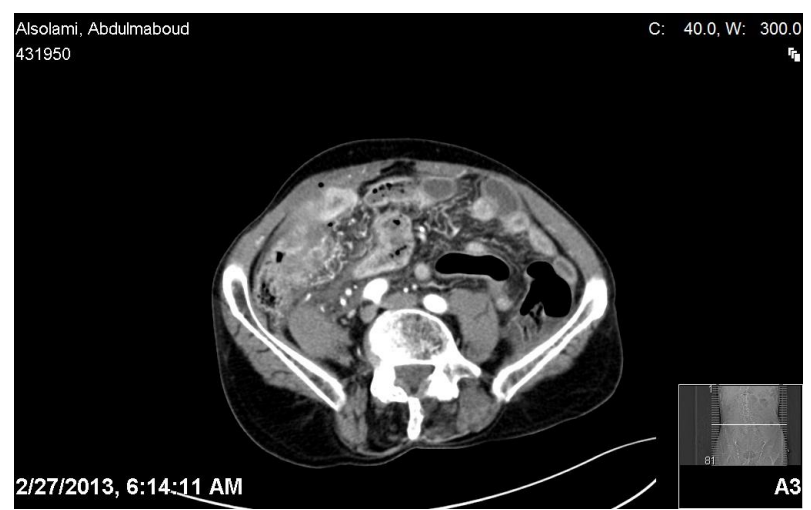

Figure 3. CT scan abdomen shows pockets of gas around caecal pole with pericaecal free fluid consistent with caecal perforation.

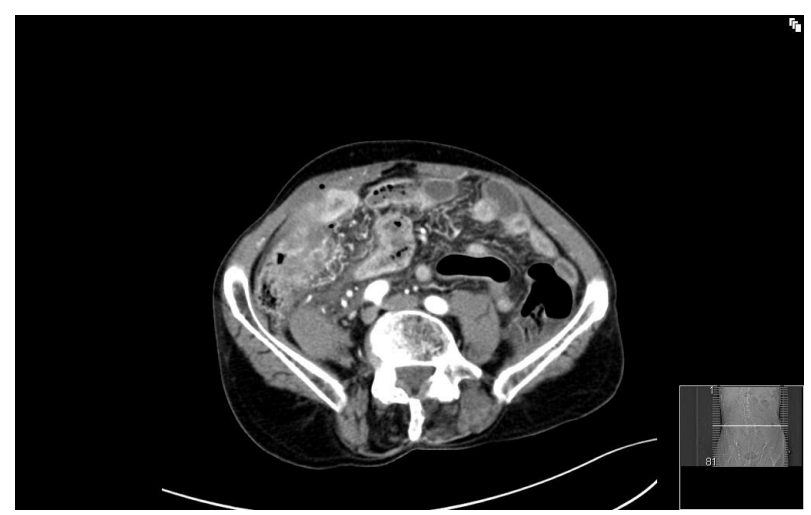

Figure 4. CT scan abdomen shows marked thickening of caecum with fat stranding and free fluid.

lavage was performed.

Postoperatively, he made uneventful recovery apart from correctable pulmonary complication \& wound infection which responded well to the local treatment with medihoney ointment dressing. Oral feeding was commenced gradually \& it was well tolerated. Histopathology report showed rounded cecal perforation with purulent yellowish discharge \& fecalith, mucosa around perforation showed oedema, submucosal congestion with no evidence of malignancy or ischaemia. Afterward he was discharged home in good condition \& followed up in the outpatient clinic.

\section{Discussion}

In 1919, Huntly reported a case of chronic constipation who collapsed during defecation due to a tear in the pelvic colon. The mean age in elderly cases is 65 years. Males are more susceptible to develop perforation with a ratio of elderly males to females 2:1. The anti-mesenteric border is the area of physiological ischaemia [7]. SPC is classified into 2 types, idiopathic \& stercoral types. Our case based on the operative findings, histopathology report as well as the outcome of the case was of idiopathic type. The idiopathic type is less common \& carries better prognosis due to minimal fecal contamination. Stercoral perforation is $1.2 \%$ of all colorectal surgical emergencies, 3.2\% of all colonic perforations. Stercoral perforation is commonly seen in chronic constipation. Maurer et al. have proposed the diagnostic features of Stercoral perforation as rounded, of more than $1 \mathrm{~cm}$ in diameter and colon is full of stool with ischemic necrosis of the surrounding mucosa \& acute inflammatory reaction. 2.3\% of all renal transplant patients are prone to SPC according to Wisconsin Medical College study [8]. Spontaneous perforation in young children is found as manifestation of EDS-IV (Ehlers-Danlos SyndromeType IV) [9]. SPC is commonly found in extreme of ages like elderly and infants [10]. 
Perforations occur more often in rectosigmoid, mid-sigmoid regions, cecum, transverse and descending colon. Maurer et al. reported that $64 \%$ of feculent perforations occur in these regions [11]. Cho et al. claimed that more than $50 \%$ of these perforations take place in sigmoid \& less common in other parts of colon [12]. Kasahara et al. mentioned that $68 \%$ of idiopathic perforations occur at these sites and these perforations are linear, with clear edges and with no microscopic evidence of ischemia [13]. Recto-sigmoid perforation was more documented in Yang et al. study as there is no ramus anastomoticus between the lower branch of sigmoid arteries \& the superior rectal artery. In young children splenic flexure, ileo-cecal, beside lower sigmoid regions were documented as areas of perforation based on their weak vasculature by Chen et al. [14]. There are anatomical vulnerable points in the colonic vasculature that have been termed as "water shed areas", like splenic flexure (Griffith's point), rectosigmoid region (Sudeck's point) \& ileocecal region [15]. Two hypotheses have been proposed to explain idiopathic perforations: Vascular theory which suggests combination of hypoperfusion of colonic tissue \& constitutional weakness of the bowel wall with increased intraluminal pressure which results from intestinal hernia, rectal prolapse, or abnormal depth of Douglas pouch [16]. Stercoral perforation is common in sigmoid, rectosigmoid regions and less commonly found in the cecum [17] [18]. Idiopathic perforation occurs due to asymmetrical distribution of intraluminal pressure at the pelvi-rectal angle in absence of obvious impacted stool or any identifiable cause of perforation [19].

The exact cause of SPC is unclear, however some conditions like, Hypothyroidism, intestinal hypomotility, chronic constipation \& fecal impaction are associated with it [20]. Colonic ischaemia due to fecal impaction is a rare condition [21]. Bartolomeo et al. [22] reported case of SPC due to chronic constipation due to chronic renal failure. Konishi et al. reported a post renal transplant case where there was perforation at rectosigmoid region [23]. Most cases of SPC are associated with connective tissue disorders such as Marfan, Ehlers-Danlos Syndrome or polyarteritis nodosa which affect collagen synthesis and also affect blood vessels.

Steroids \& non-steroidal anti-inflammatory drugs inhibit cyclo-oxygenase enzyme and result in subsequent reduction in the protective prostaglandins [24]. Drug induced fecal impaction is becoming more prevalent which may lead to SPC and these drugs are opiates, antacids, codeine, amitriptyline, and tranquilizers. Kashtan et al., reported a case of recurrent colon perforations at sigmoid \& transverse colon without any primary pathology [25]. Necrotizing enterocolitis contributes to the most perforations in neonates [26]. Clinical picture may be misdiagnosed as acute appendicitis, Crohn's disease or Tuberculous (T.B) enterocolitis. Diagnosis of SPC is based mainly on exclusion of other organic causes of perforation. A contrast-enhanced computed tomography scan demonstrates segmental thickening, pericolic fat stranding, presence of fluids in addition to assessment of vascularity of the bowel. These findings were all documented in our case report. Some authors suggested abdominal paracentesis as a valuable tool to establish diagnosis [27]. Intraoperatively, it is difficult to distinguish between types of perforation so, surgical pathological examination is necessary to make a definite diagnosis. The principle of management of SPC is prompt surgical intervention, excision of the affected segment and extensive peritoneal lavage with antibiotics [28]. Right hemicolectomy was the treatment of choice in our case being the perforation was situated in the cecum. Neoplasty with proximal colostomy or segmental resection or hemicolectomy may be more appropriate \& wise decision. Outcome of SPC management depends on the time of onset, degree of peritoneal contamination and prompt surgical intervention as mortality rate ranges between 35\% and $47 \%$. Idiopathic type of perforation has better prognosis than stercoral type, early surgical intervention markedly improves the outcome.

SPC can be avoided by some preventive measures such as, monitoring the bowel habits of the elderly, regular rectal examination, adjusting the regular dose, limiting the period of usage of non-steroidal anti-inflammatory drugs to smaller effective doses \& manual evacuation to relieve their constipation.

\section{Conclusion}

SPC is a serious condition with high morbidity and mortality due to delay in diagnosis and management so, every effort should be made to make diagnosis especially in elderly and prompt surgical intervention should be done.

\section{References}

[1] Yang, B. and Ni, H.K. (2008) Diagnosis and Treatment of Spontaneous Colonic Perforation: Analysis of 10 Cases. World Journal of Gastroenterology, 14, 4569-4572. http://dx.doi.org/10.3748/wig.14.4569 
[2] Ni, H.-K. (2008) How to Diagnose and Treat Spontaneous Colonic Perforation? Health \& Medicine.

[3] Zachariah, S.K. and Raja, N. (2010) Spontaneous Perforation of the Colon and Hypothyroidism: Report of a Case and Review of Literature. Gastroenterology Research, 3, 147-149.

[4] Sheikholeslami, F. (2009) Spontaneous Perforation of Rectosigmoid Colon. Iranian Journal of Medical Sciences, 1.

[5] Kim, E.S. and Brandt, M.L. (2013) Spontaneous Intestinal Perforation of the Newborn.

[6] Al Shukry, S. (2009) Spontaneous Perforation of the Colon Clinical Review of Five Episodes in four Patients. OMJ, 24, 137-141.

[7] Galanis, I., Dragoumis, D., Kalogirou, T., Lakis, S. and Kotakidou, R. (2010) Spontaneous Perforation of Solitary Ulcer of Transverse Colon. Indian Journal of Pathology \& Microbiology, 53, 138.

[8] Puglisi, B.S., Kauffman, H.M., Stewart, E.T., Dodds, W.T., Adams, M.B. and Komorowski, R.A. (1985) Colonic Perforation in Renal Transplant Patients. AJR. American Journal of Roentgenology, 145, 555-558. http://dx.doi.org/10.2214/ajr.145.3.555

[9] Fuchs, J.R. and Fishman, S.J. (2004) Management of Spontaneous Colonic Perforation in Ehlers-Danlos Syndrome Type IV. Journal of Pediatric Surgery, 39, e1-e3.

[10] Kumar, A., Griwan, M.G. and Naresh, P. (2013) Spontaneous Colonic Perforation-Rare Presentation. Journal of Surgical Academia, 3.

[11] Maurer, C.A., Renzulli, P., Mazzucchelli, L., Egger, B., Seiler, C.A. and Buchler, M.W. (2000) Use of Accurate Diagnostic Criteria May Increase Incidence of Stercoral Perforation of the Colon. Diseases of the Colon Rectum, 43, 991-998. http://dx.doi.org/10.1007/BF02237366

[12] Cho, H., Han, H.Y., Chun, T.J., Yu, I.K., Daejon, K.R., Daejeon, K.R. and Daejeon, R. Spontaneous Perforation of the Colon: CT Findings and Clinical Characteristics. Poster Type: Scientific Exhibit ECR 2012.

[13] Kasahara, Y., Matsumoto, H., Umemura, H., Shiraga, S. and Kuyama, T. (1981) Idiopathic Perforation of the Sigmoid Colon in Japan. World Journal of Surgery, 5, 125-130. http://dx.doi.org/10.1007/BF01657857

[14] Chen, J.-C., Chen, C.-C., Liang, J.-T. and Huang, S.-F. Spontaneous Bowel Perforation in Infants and Young Children: A Clinicopathologic Analysis of Pathogenesis. Journal of Pediatric Gastroenterology \& Nutrition, 30, 432-435.

[15] Siddharth, P. and Ravo, B. (1988) Colorectal Neurovascular and Anal Sphincter. Surgical Clinics of North America, 68, 1185-1200.

[16] Serpell, J.W. and Nicholls, R.J. (1990) Stercoral Perforation of the Colon. British Journal of Surgery, 77, $1325-1329$. http://dx.doi.org/10.1002/bjs.1800771204

[17] Basile, M., Montini, F., Cipollone, G. and Errichi, B.M. (1992) Spontaneous Perforations of the Large Intestine. Annali Italiani di Chirurgia, 63, 625-629.

[18] Velitchkov, N.G., Kjossev, K.T., Losanoff, J.E., Grigorov, G.I. and Kavardjikova-Milanova, V.A. (1995) Stercoral Perforation of the Colon. Rozhl Chir, 74, 145-146.

[19] Xu, B., Shao, W.D., Shen, H.W. and Wang, Q.B. (2004) Emergence Treatment of Idiopathic Rupture of Sigmoid Colon. Zhonghua Jizhen Yixue Zazhi, 13, 564-566.

[20] Parish, K.L., Chapman, W.C. and Williams, L.F. (1991) Ischaemic Colitis: An Ever-Changing Spectrum? Annals of Surgery, 57, 118-121.

[21] Kalayc1, M., Özder, A. and Toprak, D. (2011) Spontaneous Colon Perforation Due to Fecal Impaction. SETB, 45, 134-137.

[22] Barlemeo, R.S., Calabrese, P.R., Howard, D.R. and Taubin, L. (1977) Spontaneous Perforation of the Colon a Potential Complication of Chronic Renal Failure. The American Journal of Digestive Diseases, 22.

[23] Konishi, T., Watanabe, T., Kitayama, J., Shibahara, J., Hiramatsu, T., Hara, K., et al. (2004) Successfully Treated Idiopathic Recto Sigmoid Perforation 7 Years after Renal Transplantation. Journal of Gastroenterology, 39, 484-489. http://dx.doi.org/10.1007/s00535-003-1319-0

[24] Ervens, J., Schiffmann, L., Berger, G. and Hoffmeister, B. (2004) Colon Perforation with Acute Peritonitis after Taking Clindamycin and Diclofenac Following Wisdom Tooth Removal. Journal of Cranio-Maxillo-Facial Surgery, 32, 330 334. http://dx.doi.org/10.1016/j.jcms.2004.05.007

[25] Kashtan, H., Goldman, G., Stadler, J., Werbin, N., Baratz, M. and Wiznitzer, T. (1986) Recurrent Spontaneous Perforation of the Colon. Diseases of the Colon Rectum, 29, 586-587. http://dx.doi.org/10.1007/BF02554265

[26] Grosfeld, J.L., Molinari, F., Chaet, M., et al. (1996) Gastrointestinal Perforation and Peritonitis in Infants and Children: Experience with 179 Cases over Ten Years. Surgery, 120, 650-656. http://dx.doi.org/10.1016/S0039-6060(96)80012-2

[27] Li, M.J., Xiang, J.B. and Chen, L.L. (2001) Emergency Treatment for Colonic Perforation (29 Patients Reported). Zhongguo Linchuang Yixue, 11. 
[28] Huang, W.S., Wang, C.S., Hsieh, C.C., Lin, P.Y., Chin, C.C. and Wang, J.Y. (2006) Management of Patients with Stercoral Perforation of the Sigmoid Colon: Report of Five Cases. World Journal of Gastroenterology, 12, 500-503.

[29] Spiliotis, J. (2008) Idiopathic Spontaneous Perforation of the Sigmoid Colon or a Complication of Sexual Activity? World Journal of Gastroenterology. 
Scientific Research Publishing (SCIRP) is one of the largest Open Access journal publishers. It is currently publishing more than 200 open access, online, peer-reviewed journals covering a wide range of academic disciplines. SCIRP serves the worldwide academic communities and contributes to the progress and application of science with its publication.

Other selected journals from SCIRP are listed as below. Submit your manuscript to us via either submit@scirp.org or Online Submission Portal.
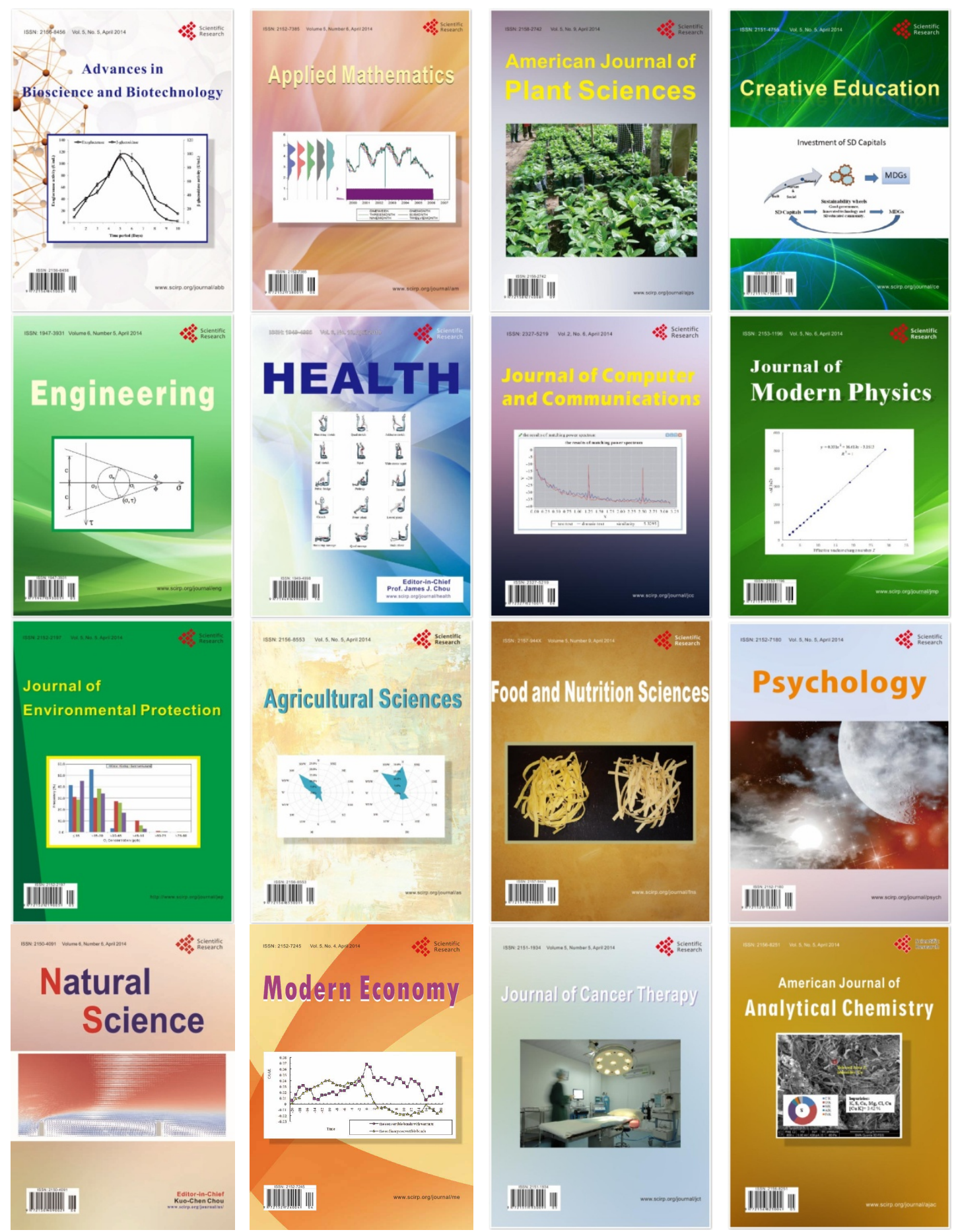